AIAA-2002-1416

\title{
THERMAL/MECHANICAL RESPONSE AND DAMAGE GROWTH IN POLYMERIC COMPOSITES AT CRYOGENIC TEMPERATURES ${ }^{1}$
}

\author{
Karen S. Whitley ${ }^{\dagger}$ and Thomas S. Gates ${ }^{*}$ \\ NASA Langley Research Center \\ Hampton, VA 23681
}

\begin{abstract}
$\underline{\text { Abstract }}$
In order to increase the reliability of the next generation of space transportation systems, the mechanical behavior of polymeric matrix composite (PMC) materials at cryogenic temperatures must be investigated. This paper presents experimental data on the residual mechanical properties of a carbon fiber polymeric composite, IM7/PETI-5 both before and after aging at cryogenic temperatures. Tension modulus and strength were measured at room temperature, $-196^{\circ} \mathrm{C}$, and $-269^{\circ} \mathrm{C}$ on five different specimen ply lay-ups, $[0]_{12},[90]_{12},[ \pm 45]_{3 \mathrm{~s}},[ \pm 25]_{3 \mathrm{~s}}$ and $\left[45,90_{3},-45,0_{3},-\right.$ $\left.45,90_{3}, 45\right]$. Specimens were preconditioned with one set of coupons being isothermally aged for 555 hours at $-184^{\circ} \mathrm{C}$ in an unloaded state. Another set of corresponding coupons were mounted in constant displacement fixtures such that a constant uniaxial strain was applied to the specimens for 555 hours at $-184^{\circ} \mathrm{C}$. The measured lamina level properties indicated that cryogenic temperatures have an appreciable influence on behavior, and residual stress calculations based on lamination theory showed that the transverse tensile ply stresses could be quite high for cryogenic test temperatures. Microscopic examination of the surface morphology showed evidence of degradation along the exposed edges of the material due to aging at cryogenic temperatures.
\end{abstract}

\section{Introduction}

The National Aeronautics and Space Administration (NASA) has recently initiated the Space Launch Initiative (SLI) program that will, in part, advance some

\footnotetext{
${ }^{\dagger}$ Aerospace Engineer, Mechanics and Durability Branch.

* Senior Materials Research Engineer, Mechanics and Durability Branch. Associate Fellow, AIAA.

${ }^{1}$ Copyright 2001 by the American Institute of Aeronautics and Astronautics, Inc. No copyright is asserted in the United States under Title 17, U.S. Code. The U.S. Government has a royalty-free license to exercise all rights under the copyright claimed herein for Government Purposes. All other rights are reserved by the copyright owner.
}

of the key technologies required for the next generation of launch vehicles. This next generation of space transportation systems may require both reusable launch vehicles (RLV's) and expendable launch vehicles (ELV's) to satisfy mission requirements. One of the key technologies identified for RLV's and ELV's has been the reduction in structural weight through the use of advanced materials and manufacturing methods. This reduction in structural weight must be tempered against the increased demands on performance, damage tolerance, and lifetime durability.

One potential source for structural weight reduction is the replacement of traditional metallic cryogenic fuel tanks with polymeric matrix composite (PMC) tanks. The interest in design of polymeric composite, cryogenic-fuel tanks for launch vehicles goes back several years and includes research associated with the National Aerospace Plane (NASP), single-stage-toorbit (SSTO) vehicles [1]-[3], and other launch vehicle applications [4]. For internal and external tanks, design of the tank may take the form of externally stiffened shells of PMC material or thin-walled sandwich shell constructed with lightweight core and PMC facesheets. Regardless of the design, the PMC-based tanks will be required to safely carry pressure and flight loads and operate over temperatures that may range from $-250^{\circ} \mathrm{C}$ to $+120^{\circ} \mathrm{C}$. From a durability perspective, the primary performance criteria of the PMC material is to retain mechanical properties within allowable limits over the life-time of the tank while minimizing loss of cryogenic fuel due to permeation or leakage through the tank wall.

Aside from their use in space launch vehicles, there have been very few applications of PMC's as structural materials in cryogenic environments. Consequently, a search of the available literature provides limited experimental data on the mechanical properties of polymers or PMC's operating at cryogenic temperatures. For amorphous and crystalline polymeric materials, Perepechko [5] provides details on a number of non-mechanical properties including thermal expansion, thermal conductivity, as well as viscoelastic or dynamical mechanical properties. From these studies, it was clear that many of the polymer properties are not linear with respect to temperature 
change from room temperature to close to absolute zero.

In the work by Pannkoke [6] fatigue tests were performed on unidirectional thermoplastic composites at $-196^{\circ} \mathrm{C}$. The fatigue strength was found to be only $60 \%$ of the static strength at $10^{6}$ cycles. In this work, it was recognized that large thermal stresses degraded the fatigue performance. In a series of articles by Alhborn [7], [8], static and cyclic thermal/mechanical tests were performed on unidirectional and cross-ply thermoplastic composites. Isothermal tests were performed at $23^{\circ} \mathrm{C}$, $-196^{\circ} \mathrm{C}$, and $-269^{\circ} \mathrm{C}$ and cyclic thermal tests were performed between $-196^{\circ} \mathrm{C}$ and $23^{\circ} \mathrm{C}$. Strength, damage, and fatigue life were measured for all test conditions. It was found that the effects of temperature on static strength were largely related to the matrix dominated properties, shear and transverse tension, and that increases in matrix dominated strength as temperature decreased could be offset by the development of thermal-stress induced cracks. As in previous studies, the fatigue life was reduced as the test temperature was decreased.

More recently, a compilation of test data for several PMC material systems [9] showed that in general, tensile modulus, tensile strength, and compressive strength all increased as the test temperature was decreased from $23^{\circ} \mathrm{C}$ to $-269^{\circ} \mathrm{C}$. Once again, it was found that thermal stresses had a large influence on behavior and that the sensitivity of matrix-dominated properties to temperature can be used to help explain the stress-strain response of laminated composites. Of these matrix-dominated properties, transverse ply strength may play a critical role in the development and growth of residual stress induced matrix cracks. The range of thermal/mechanical loading over which steady-state matrix cracking may occur was investigated recently by Schoeppner [10]. Additional studies related to matrix crack development in PMC's due to cryogenic temperature exposure can be found in [11].

It is the intent of this paper to contribute to the knowledge base on performance of PMC's in cryogenic environments by providing experimental data and test methods developed from a series of thermal/mechanical tests. The selected test conditions represent a range of exposure times, loads and temperatures similar to those experienced during the lifetime of a cryogenic, hydrogen fuel tank. Results will be given for tensionloaded coupons subjected to temperatures that ranged from room temperature to $-269^{\circ} \mathrm{C}$. Fundamental, lamina-level material properties were measured, analyzed, and correlated against test environment. Residual stiffness and strength, and damage as measured by microcrack density, will be given as a function of both cryogenic test temperatures and pre-test cryogenic aging conditions. The material used in the study, (IM7/PETI-5), is an advanced carbon fiber, thermoplastic polyimide composite similar in behavior to a number of high performance PMC's.

It is recognized that a broad spectrum of factors influence the properties of PMC's including material selection, composite fabrication and handling, aging or preconditioning, specimen preparation, laminate ply lay-up, test procedures, etc. This study will focus on test temperature, preconditioning methods, and laminate configuration as the primary test variables. It is expected that the results of this study will aid in the development of future material qualification methods and design verification testing.

\section{Material System}

The PMC material used in this study, IM7/PETI5 , consisted of a continuous high strength, intermediate modulus, carbon fiber in a thermoplastic polyimide matrix. All test materials were laminated composites fabricated at the NASA Langley Research Center. These composite panels consisted of unidirectional and angle-ply laminates, $\left([0]_{12},[90]_{12},[ \pm 25]_{3 \mathrm{~s}},[ \pm 45]_{3 \mathrm{~s}}\right)$, and a 13-ply quasi-orthotropic laminate ([45/90 $/$ $\left.45 / \overline{0}_{3} l_{S}\right)$. The bar notation over the 0 indicates that the $0_{3}$ ply group is not symmetric. Figure 1 provides a schematic illustrating the coordinate system for the fiber orientations relative to the specimen dimensions.

These lay-ups were chosen to provide basic laminalevel material constants and in the case of the $\left[45 / 903 /-45 / \overline{0}_{3}\right]_{\mathrm{S}}$ laminate, to be representative of a composite wall in a typical cryogenic propellant tank. For a cryogenic tank, the orientation of the $0^{\circ}$ ply in the $\left[45 / 90_{3} /-45 / \overline{0}_{3}\right]_{S}$ laminate would be in the longitudinal axis direction of the tank.

All composite panels were fabricated by hand layup. The bagging and cure processes employed were consistent with standard practices. The cure cycle consisted of a $240 \pm 10$ minute hold at $177^{\circ} \mathrm{C}\left(350^{\circ} \mathrm{F}\right)$, a $120 \pm 10$ minute hold at $260^{\circ} \mathrm{C}\left(500^{\circ} \mathrm{F}\right)$ under full vacuum, followed by pressurization of the autoclave to $1480 \pm 35 \mathrm{kPa}(200 \pm 5 \mathrm{psig})$ at $170 \pm 14 \mathrm{kPa} /$ minute $(10$ $\pm 2 \mathrm{psig} /$ minute) during ramp to $370^{\circ} \mathrm{C}\left(700^{\circ} \mathrm{F}\right)$ for 60 \pm 10 minutes. Through-transmission, ultrasonic inspection indicated that there were no significant internal anomalies in any of the panels. The glass transition temperature $\left(\mathrm{T}_{g}\right)$ of the as-received composite material was $267^{\circ} \mathrm{C}$ as measured by the peak in the Tan $\delta$ curve of tests run in a dynamic mechanical analysis (DMA) test [12].

\section{Material Characterization}

The material characterization test plan consisted of two phases. The first phase addressed material aging. In this phase the material was subjected to long- 
term exposure at cryogenic temperature in either an unloaded or statically loaded state. The second phase was residual property characterization of aged and not aged specimens at three temperatures $\left(23^{\circ},-196^{\circ}\right.$, and $-269^{\circ} \mathrm{C}$ ). This phase provided fundamental material properties and an understanding of material behavior as a function of prior aging conditions and test temperatures. The complete test matrix including the phase one aging conditions and the phase two residual property tests are shown in table 1 .

All tests were conducted on coupon type test

specimens that were cut from the larger panels prior to aging. Three replicates of each condition were tested for generating the data. A schematic of the test coupon is presented in figure 1 .

The general set of references for the residual

tension test is SACMA SRM 4-88 and ASTM D 303976. Data reduction on all residual mechanical property tests was done in accordance with the individual test standards. A basic description of each type of test is provided below. The tensile modulus was calculated using ASTM D3039-76 and a linear regression least squares curve fit of the stress-strain data in the linear region. The linear region of the stress-strain curve was most commonly defined as being between $1000 \mu \varepsilon$ and

$3000 \mu \varepsilon$ for all test conditions and specimen ply lay-ups.

\section{Test phase one - Material aging}

A unique test fixture developed under the NASA High Speed Research Program [13] was used to produce a constant strain condition during the aging phase. Each fixture, shown in figure 2, was constructed of Invar material $\left(\mathrm{CTE}=1.4 \mu \mathrm{mm} / \mathrm{mm}-{ }^{\circ} \mathrm{C}\right)$ and could accommodate two rectangular specimens. Each specimen was individually preloaded to the desired strain level by compressing a series of spring-type washers that react against the frame and put the specimen into tension. As the specimen was preloaded and the washers were tightened, the strain in the specimen was monitored with a longitudinal extensometer mounted on the specimen.

The preload strain level, given in table 1, was selected to be approximately $50 \%$ of the room temperature failure strain. The high stiffness of the fixture relative to the test specimen and the low CTE of the Invar material ensured a constant strain condition over the entire aging period. A corresponding set of coupons were aged in an unloaded condition. During the course of an aging phase the constant strain fixtures and unloaded coupons were placed into a large cryochamber that maintained a constant temperature of $-184^{\circ} \mathrm{C}$ for an aging time of 555 hours.
Test phase two - Residual properties

In phase two of the test program, residual strength and stiffness were measured after aging. All residual property tests were performed in tension on a servohydraulic test machine using a displacement rate of $1.27 \mathrm{~mm} / \mathrm{min}$. The isothermal cryogenic test conditions at $-196^{\circ} \mathrm{C}$ and $-269^{\circ} \mathrm{C}$ were achieved by immersing the test specimen and load introduction apparatus into liquid nitrogen or liquid helium respectively. In order to reach thermal equilibrium, the specimen stayed immersed in a constant level of the cryogen for at least 15 minutes prior to mechanical loading.

Stress in the test specimens was calculated using load, as measured by the test machine load cell, divided by the original cross section of the specimen. Strain in the test specimen was measured using combinations of cryogenic-rated axial extensometers (MTS model 634.11F-21) and bonded electrical resistance strain gages (Measurements Group WK-00-250BG-350). Temperature compensation was achieved by zeroing the extensometer and gages after the specimen reached thermal equilibrium. Details on these techniques can be found in reference [14]. Placement of these sensors on the specimen is shown in figure 1.

Prior to aging exposure, representative samples were polished along one edge. Optical microscopy was used to investigate for damage (microcracks, delaminations), and photomicrographs were taken to establish the baseline condition. After aging exposure, but prior to the destructive residual tests, visual examination of all lay-ups was again performed to determine if the exposure conditions generated any microcracks, damage, or change in surface morphology. Photomicrographs representative of the specimen's edge before and after aging are shown in figure 3 .

\section{Residual Stress Analysis}

As shown by many of the studies cited in the Introduction section, in the absence of mechanical loading, thermal stresses alone may be sufficient to influence laminate performance. For thermal loading, stresses are induced at the ply level due to expansion or contraction and constraining effects of adjacent plies that prevent a free expansion or contraction. The residual stress in any ply can be calculated using classical laminated plate theory [15]. In general, for a laminated, unidirectional plate under plane stress, the constitutive relationship includes the combination of the mechanical and thermal strains

$$
\{\sigma\}=[Q]\left(\left\{\varepsilon^{M}\right\}-\left\{\varepsilon^{T}\right\}\right)
$$


where $\sigma$ is the stress, $Q$ is the material stiffness matrix, $\varepsilon^{M}$ is the mechanical strain and $\varepsilon^{T}$ is the thermal strain. For a single lamina or ply, this thermal strain is calculated using

$$
\left\{\begin{array}{c}
\varepsilon_{11}^{T} \\
\varepsilon_{22}^{T} \\
\gamma_{12}^{T}
\end{array}\right\}=\left\{\begin{array}{c}
\alpha_{1} \\
\alpha_{2} \\
0
\end{array}\right\} \Delta T
$$

where $\varepsilon$ is the normal strain, $\gamma$ is the shear strain, $\alpha$ is the coefficient of thermal expansion (CTE), and $\Delta T$ is the temperature differential between the test condition and the stress free condition at cure. Subscripts in equation (2) refer to the standard notation ( $1=$ fiber direction, $2=$ transverse direction).

Clearly, from equation (2) it is apparent that for large values of $\Delta T$, a condition at cryogenic temperatures, the magnitude of the thermal induced strains is highly dependent on the material CTE values. In particular, nonlinear behavior of the CTE with respect to temperature, as illustrated in table 2 , may result in thermal residual stresses that also vary in a nonlinear manner with respect to temperature. To illustrate this effect, material properties given in table 3 and CTE values derived from [16] (provided in table 2) were used as inputs to classical laminated plate theory to predict the maximum transverse ply stress as a function of laminate stacking sequence, test temperature, and laminate preconditioning. The results of these calculations are given in table 4 . It should be noted that not-aged CTE values were used for all conditions and the stress-free temperature was assumed to be the glass transition temperature of IM7/PETI-5.

With respect to temperature, table 4 indicates that the trend for the not-aged condition is for transverse stress to increase with a decrease in temperature. However, both of the isothermal-aged conditions predict the largest stress to occur at the intermediate temperature $\left(-196^{\circ} \mathrm{C}\right)$. With respect to ply lay-up, the highly constrained $\left[45 / 90_{3} /-45 / \overline{0}_{3}\right]_{S}$ is predicted to have the highest stress at any given temperature, however the angle-ply laminate $[ \pm 45]_{3 \mathrm{~S}}$ has stress magnitudes close to the $\left[45 / 90_{3} /-45 / \overline{0}_{3}\right]_{s}$. With respect to precondition, no clear trends are evident.

\section{$\underline{\text { Results and Discussion }}$}

In this paper, elastic modulus and residual strength results are presented for laminates with $[0]_{12},[ \pm 45]_{3 \mathrm{~S}}$, and $\left[45 / 90_{3} /-45 / \overline{0}_{3}\right]_{s}$ ply stacking sequence. In the graphs presented, (figure 4-9) both modulus and strength values have been normalized against the not aged condition tested at room temperature for each laminate.

Table 3 contains the elastic modulus at the three different test temperatures, for each lay-up for each aging condition. Each value in the table represents the average of three replicates along with the standard deviation. The lamina in-plane stiffness values $E_{1}$ and $\mathrm{E}_{2}$, were calculated directly from stress-strain behavior of the unidirectional laminates, $[0]_{12}$ and $[90]_{12}$, respectively. The laminate stiffness value $E_{x}$ of the laminates $[ \pm 25]_{3 S}$ and $\left[45 / 900_{3} /-45 / \overline{0}_{3}\right]_{S}$, was calculated from the laminate stress-strain behavior. Lamina inplane shear modulus $G_{12}$ was calculated indirectly from the stress-strain behavior of the $[ \pm 45]_{3 \mathrm{~S}}$ laminate using the equation,

$$
G_{12}=\frac{E_{x}}{2\left(1+v_{x y}\right)}
$$

where $v_{x y}$ is the laminate Poisson's ratio and $E_{x}$ is the laminate longitudinal modulus.

Measured laminate strength values are listed in table 5. Failure was defined as the point of complete loss of load carrying capability during the tensile test. Due to the nonlinear nature of the stress-strain behavior in $[ \pm 45]_{3 \mathrm{~s}}$ laminates, their strength was defined as the initial point of deviation from the tangent to the slope of the stress-strain curve where it became nearly horizontal.

\section{Effect of Temperature on Modulus and Strength}

By examining the results from specimens subjected to not-aged test condition, the effects of temperature on modulus and strength can be found. The fiber dominated laminate with $[0]_{12}$ plies experienced a decrease in both the modulus and strength due to testing at cryogenic temperatures with up to a $35 \%$ decrease in strength for the $-196^{\circ} \mathrm{C}$ case. Conversely, the shear modulus and longitudinal strength of the matrix dominated $[ \pm 45]_{3 \mathrm{~s}}$ laminate increased as the temperature decreased. The shear modulus increased by as much as $35 \%$ and the strength by as much as $50 \%$ when tested at $-269^{\circ} \mathrm{C}$. The transverse modulus $\left(\mathrm{E}_{2}\right)$ showed a slight decline at cryogenic temperatures while the transverse strength dropped by approximately $70 \%$ when the temperature was reduced to $-269^{\circ} \mathrm{C}$.

The modulus and strength of the not aged $\left[45 / 90_{3} /-\right.$ $\left.45 / \overline{0}_{3}\right]_{\mathrm{s}}$ decreased by nearly $20 \%$ at $-196^{\circ} \mathrm{C}$, with some reverse in this decline as the temperature was lowered to $-269^{\circ} \mathrm{C}$. The $[ \pm 25]_{3 \mathrm{~S}}$ laminate showed little sensitivity in modulus or strength to cryogenic temperature. 


\section{Effect of Aging on Modulus and Strength}

To determine the effects of aging, the not aged condition can be compared to the aged without load and the aged with load conditions. In general aging had very little effect on the modulus of the fiber dominated $[0]_{12}$-ply laminate. Aging did cause a slight increase in strength for the $[0]_{12}-$ ply laminate with the most significant change occurring when tested at $-269^{\circ} \mathrm{C}$ after aging with load. Aging did not significantly effect the shear modulus or longitudinal strength of the matrix dominated $[ \pm 45]_{3 \mathrm{~S}}$-ply laminate.

For the laminate with the ply stacking sequence, $\left[45 / 903 /-45 / \overline{0}_{3}\right]_{S}$ aging increased the modulus. The largest increase $(18 \%)$ occurred for the laminate aged with load condition tested at $-269^{\circ} \mathrm{C}$. Aging also increased the strength of the $\left[45 / 90_{3} /-45 / \overline{0}_{3}\right]_{\mathrm{s}}-$ ply laminate with the most significant increase occurring at the aged with load condition where strength increased relative to the baseline by $21 \%$ at $-196^{\circ} \mathrm{C}$ and $11 \%$ at $-269^{\circ} \mathrm{C}$. In general, aging decreased the modulus of the $[ \pm 25]_{3 \text { s }}$-ply laminate and had little effect on the laminate strength. From the limited data for the $[90]_{12}$ -ply laminate, it appears that aging had little effect on transverse modulus or strength.

As expected, the standard deviation in strength measurements was more significant than the standard deviation associated with modulus. In part, this is due to strength being a point or single value whereas modulus is an averaged value based on the trend in a curve. Strength in laminated composites is also more sensitive to the processing, handling, or test parameter variability.

\section{Surface Morphology}

Optical examination of surface morphology was intended to provide data on the initiation and growth of any damage that occurred during specimen aging. Photomicrographs of the specimen's polished edges taken during this study are shown in figure 3 . The photos in the first column are not aged material, the second column are specimens that have been aged without load, and the third column are specimens that have been aged with load. Very few microcracks or similar damage were observed before or after aging in any of the lay-ups. However, the surface morphology shows some definite degradation along the exposed edges after aging without load and it appears that further surface degradation occurs after aging with load. This degradation occurred in all lay-ups and can be described as pitting in the matrix regions.

\section{Summary and Conclusions}

Five different laminate configurations of IM7/PETI-5 were evaluated for tensile strength and stiffness at room temperature and two cryogenic test temperatures. The effects of laminate configuration, test temperature, and preconditioning or aging were investigated. Aging consisted of 555 hours exposure in a $-184^{\circ} \mathrm{C}$ environment both with and without mechanical load. Specimens were also examined for evidence of damage or microcracking before and after aging.

Examination of the basic lamina properties such as strength and stiffness in the longitudinal, transverse, and shear directions indicates that cryogenic temperatures can have an appreciable influence on behavior. Longitudinal and transverse stiffness and strength will decrease as the test temperature is decreased. Shear modulus and strength will increase as the temperature is decreased. The lamination stacking sequences such as the $\left[45 / 90_{3} /-45 / \overline{0}_{3}\right]_{\mathrm{S}}$ and $[ \pm 25]_{3 \mathrm{~S}}$ are less influenced by temperature. The highly constrained $\left[45 / 90_{3} /-45 / \overline{0}_{3}\right]_{s}-$ ply laminate is more sensitive to cryogenic temperatures than the $[ \pm 25]_{3 s}$-ply laminate. Residual stress calculations based on lamination theory showed that the transverse tensile ply stresses can be quite high for cryogenic test temperatures with the angle-ply and more practical laminates generating the highest values of residual stress. These transverse residual stresses may lower potential strength and stiffness by accelerating the initiation and growth of transverse microcracks in a ply.

Aging the material under isothermal, cryogenic temperature will cause changes in the strength and stiffness as compared to the not aged or as-received condition. In general, it appears that this type of aging will increase both strength and stiffness regardless of laminate lay-up. Of particular interest, it appears that isothermal cryogenic aging while under a constant strain condition will produce some additional increase in strength and stiffness as compared to aging in an unloaded condition. For the IM7/PETI-5 material, aging at cryogenic temperatures also produces a degradation in the matrix material along the exposed edges. This degradation may have an adverse influence on residual strength due to the increase in possible failure initiation sites. 


\section{References}

1. Morino, Y., "Feasibility Study of CFRP Material Application to the Cryogenic Propellant Tank of Reusable Launch Vehicles," Japan International SAMPE Symposium, 1999.

2. Robinson, M. J., "Composite Cryogenic Propellant Tank Development, " $35 \mathrm{th}$ AIAA/ASME/ASCE/AHS/ASC Structural Dynamics, and Materials Conference, 1994. Hilton Head, South Carolina.

3. Robinson, M. J., "Composite Structures on the DC-XA Reusable Launch Vehicle," 28th International SAMPE, 1996. Seattle, Washington.

4. Callaghan, M. T., "Use of resin composites for cryogenic tankage," Cryogenics, 1991. 31(4) pp. 282-287.

5. Perepechko, I., Low-Temperature Properties of Polymers. 1997, Moscow, Mir Publishers.

6. Pannkoke, K. and Wagner, H. J., "Fatigue properties of unidirectional carbon fiber composites at cryogenic temperatures," Cryogenics, 1991. 31(4), pp. 248-251.

7. Ahlborn, K., "Durability of carbon fibre reinforced plastics with thermoplastic matrices under cyclic mechanical and cyclic thermal loads at cryogenic temperatures," Cryogenics, 1991. 31(4), pp. 257 260.

8. Ahlborn, K., "Cryogenic mechanical response of carbon fibre reinforced plastics with thermoplastic matrices to quasi-static loads," Cryogenics, 1991. 31(4), pp. 252-256.
9. Schutz, J. B., "Properties of composite materials for cryogenic applications," Cryogenics, 1998. 38(1), pp. 3-12.

10. Schoeppner, G. A., Kim, R., and Donaldson, S. L., "Steady State Cracking of PMC's at Cryogenic $\mathrm{T}$ e m p e r a t u r e s," $42 \mathrm{nd}$ AIAA/ASME/ASCE/AHS/ASC Structural Dynamics, and Materials Conference, 2001. Seattle, WA.

11. Shimoda, T., "Study of CFRP Application to the Cryogenic Propellant Tank of Reusable Launch Vehicle," 42nd AIAA/ASME/ASCE/AHS/ASC Structural Dynamics, and Materials Conference, 2001. Seattle, WA.

12. Kampf, G., Characterization of Plastics by Physical Methods, Experimental Techniques, and Practical Application, 1986. Munich, Hanser.

13. Council, N.R., ed., U.S. Supersonic Commercial Aircraft. Committee on High Speed Research Aeronautics and Space Engineering Board, 1997. National Academy Press, Washington, D.C.

14. Dally, J. W. and Riley, W. F., Experimental Stress Analysis. 2nd ed., 1978. New York, McGraw-Hill Book Company.

15. Jones, R. M., Mechanics of Composite Materials. 1975, Washington, D.C., Scripta Book Company.

16. Johnson, T. F. and Gates, T. S., "Temperature Polyimide Materials in Extreme Temperature E n v i r n m e $\mathrm{n} \mathrm{s}$," $42 \mathrm{nd}$ AIAA/ASME/ASCE/AHS/ASC Structural Dynamics, and Materials Conference, 2001. Seattle, WA.

Table 1. Test matrix illustrating the residual test temperature and aging condition for each type of laminate

\begin{tabular}{|c|c|c|c|}
\hline \multirow{2}{*}{$\begin{array}{c}\text { Test } \\
\text { temperature } \\
\left({ }^{\circ} \mathrm{C}\right)\end{array}$} & \multicolumn{3}{|c|}{ Aging condition $\left(-184^{\circ} \mathrm{C}\right)$} \\
\hline & No load & $\begin{array}{l}\text { Static load } \\
(3000 \mu \varepsilon)\end{array}$ & $\begin{array}{l}\text { Static load } \\
(4000 \mu \varepsilon)\end{array}$ \\
\hline 23 & $\begin{array}{c}{[0]_{12},[90]_{12}} \\
{[ \pm 45]_{3 \mathrm{~s}},[ \pm 25]_{3 \mathrm{~s}}} \\
{\left[45 / 90_{3} /-45 / \overline{0}_{3}\right]_{\mathrm{s}}}\end{array}$ & $\begin{array}{c}{[ \pm 45]_{12},} \\
{[0]_{12}}\end{array}$ & $\begin{array}{c}{[ \pm 25]_{3 \mathrm{~s}}} \\
{\left[45 / 90_{3} /-45 / \overline{0}_{3}\right]_{\mathrm{s}}}\end{array}$ \\
\hline-196 & $\begin{array}{c}{[0]_{12},[90]_{12}} \\
{[ \pm 45]_{3 \mathrm{~s}},[ \pm 25]_{3 \mathrm{~s}}} \\
{\left[45 / 90_{3} /-45 / \overline{0}_{3}\right]_{\mathrm{s}}}\end{array}$ & $\begin{array}{c}{[ \pm 45]_{12},} \\
{[0]_{12}}\end{array}$ & $\begin{array}{c}{[ \pm 25]_{3 \mathrm{~s}}} \\
{\left[45 / 90_{3} /-45 / \overline{0}_{3}\right]_{\mathrm{s}}}\end{array}$ \\
\hline-269 & $\begin{array}{c}{[0]_{12},[90]_{12}} \\
{[ \pm 45]_{3 \mathrm{~s}},[ \pm 25]_{3 \mathrm{~s}}} \\
{\left[45 / 90_{3} /-45 / \overline{0}_{3}\right]_{\mathrm{s}}}\end{array}$ & $\begin{array}{c}{[ \pm 45]_{12}} \\
{[0]_{12}}\end{array}$ & $\begin{array}{c}{[ \pm 25]_{3 \mathrm{~s}}} \\
{\left[45 / 90_{3} /-45 / \overline{0}_{3}\right]_{\mathrm{s}}}\end{array}$ \\
\hline
\end{tabular}

6

American Institute of Aeronautics and Astronautics 
Table 2. Coefficient of thermal expansion for not aged IM7/PETI-5 material system

\begin{tabular}{ccc}
\hline & \multicolumn{2}{c}{$\mu \mathrm{mm} / \mathrm{mm}-{ }^{\circ} \mathrm{C}$} \\
\cline { 2 - 3 } Temp $\left({ }^{\circ} \mathrm{C}\right)$ & {$[0]_{12}$} & {$[90]_{12}$} \\
\cline { 2 - 3 } 24 & -1.50 & 35.00 \\
-196 & 1.37 & 27.54 \\
-273 & 2.60 & 14.60 \\
\hline \hline
\end{tabular}

Table 3. Measured elastic modulus values

\begin{tabular}{|c|c|c|c|c|c|}
\hline $\begin{array}{l}\text { Specimen ply } \\
\text { lay - up }\end{array}$ & $\underset{{ }^{\circ} \mathrm{C}}{\mathrm{Temp}}$ & $\begin{array}{l}\text { Material } \\
\text { property }\end{array}$ & $\begin{array}{c}\text { Not aged } \\
\text { modulus (GPa) } \\
\pm \text { Std dev. } \\
\end{array}$ & $\begin{array}{l}\text { Aged without load } \\
\text { modulus }(\mathrm{GPa}) \\
\pm \text { Std dev. }\end{array}$ & $\begin{array}{c}\text { Aged with load } \\
\text { modulus (GPa) } \\
\pm \text { Std dev. }\end{array}$ \\
\hline$[0]_{12}$ & 24 & $\mathrm{E}_{1}$ & $158 \pm 9$ & $154 \pm 6$ & $147 \pm 3$ \\
\hline$[0]_{12}$ & -196 & $\mathrm{E}_{1}$ & $152 \pm 2$ & $146 \pm 11$ & $149 \pm 2$ \\
\hline$[0]_{12}$ & -269 & $\mathrm{E}_{1}$ & $145 \pm 7$ & $143 \pm 9$ & $159 \pm 21$ \\
\hline$[ \pm 25]_{3 \mathrm{~S}}$ & 24 & $\mathrm{E}_{\mathrm{x}}$ & $72 \pm 1$ & $70 \pm 2$ & $60 \pm 3$ \\
\hline$[ \pm 25]_{3 \mathrm{~S}}$ & -196 & $\mathrm{E}_{\mathrm{x}}$ & $76 \pm 1$ & $64 \pm 8$ & $71 \pm 3$ \\
\hline$[ \pm 25]_{3 \mathrm{~s}}$ & -269 & $\mathrm{E}_{\mathrm{x}}$ & $73 \pm 4$ & 69 & $66 \pm 12$ \\
\hline$\left[45 / 90_{3} /-45 / \overline{0}_{3}\right]_{\mathrm{S}}$ & 24 & $\mathrm{E}_{\mathrm{x}}$ & $51 \pm 1$ & $47 \pm 4$ & $51 \pm 1$ \\
\hline$\left[45 / 90_{3} /-45 / \overline{0}_{3}\right]_{\mathrm{S}}$ & -196 & $\mathrm{E}_{\mathrm{x}}$ & $41 \pm 6$ & $48 \pm 2$ & $49 \pm 3$ \\
\hline$\left[45 / 90_{3} /-45 / \overline{0}_{3}\right]_{\mathrm{S}}$ & -269 & $\mathrm{E}_{\mathrm{x}}$ & $44 \pm 2$ & $44 \pm 4$ & $52 \pm 1$ \\
\hline$[90]_{12}$ & 24 & $\mathrm{E}_{2}$ & $8.7 \pm 0.1$ & $8.6 \pm 0.1$ & NA \\
\hline$[90]_{12}$ & -196 & $\mathrm{E}_{2}$ & $7.5 \pm 0.1$ & $9.5 \pm 2$ & $9.6 \pm 0.1$ \\
\hline$[90]_{12}$ & -269 & $\mathrm{E}_{2}$ & $7.8 \pm 1.2$ & $7.1 \pm 0.8$ & NA \\
\hline$[ \pm 45]_{3 \mathrm{~S}}$ & 24 & $\mathrm{G}_{12}$ & $4.6 \pm 0.4$ & $5.0 \pm 0.1$ & $5.8 \pm 0.2$ \\
\hline$[ \pm 45]_{3 \mathrm{~S}}$ & -196 & $\mathrm{G}_{12}$ & $5.8 \pm 0.1$ & $6.2 \pm 0.1$ & $6.0 \pm 0.2$ \\
\hline$[ \pm 45]_{3 \mathrm{~S}}$ & -269 & $\mathrm{G}_{12}$ & $6.2 \pm 0.2$ & $5.5 \pm 0.9$ & $6.1 \pm 0.3$ \\
\hline
\end{tabular}

(NA $=$ not available) 
Table 4. Calculated maximum transverse ply stress for thermal loading only

\begin{tabular}{cccccc}
\hline & & \multicolumn{5}{c}{ Maximum transverse ply stress (MPa) } \\
\cline { 3 - 6 } Precondition & $\mathrm{T}\left({ }^{\circ} \mathrm{C}\right)$ & {$[0]_{12}$} & {$[ \pm 25]_{3 \mathrm{~s}}$} & Ortho-A & {$[ \pm 45]_{3 \mathrm{~s}}$} \\
\cline { 3 - 6 } & & & & & \\
\hline \multirow{2}{*}{ Unaged } & 24 & 0.0 & 31.8 & 72.0 & 70.9 \\
& -196 & 0.0 & 37.7 & 70.3 & 69.3 \\
& -269 & 0.0 & 45.0 & 83.0 & 81.7 \\
\hline \multirow{2}{*}{ Iso-aged without load } & 24 & 0.0 & 33.3 & 71.0 & 70.0 \\
& -196 & 0.0 & 43.3 & 87.4 & 85.8 \\
& -269 & 0.0 & 40.7 & 75.9 & 74.8 \\
\hline Iso-aged with load & 24 & 0.0 & 24.4 & 71.0 & 69.7 \\
& -196 & 0.0 & 43.1 & 88.4 & 86.8 \\
& -269 & 0.0 & 42.7 & 76.4 & 75.4 \\
\hline \hline
\end{tabular}

Table 5. Measured strength values

\begin{tabular}{ccccc}
\hline $\begin{array}{c}\text { Specimen ply } \\
\text { lay- up }\end{array}$ & $\begin{array}{c}\text { Temp } \\
{ }^{\circ} \mathrm{C}\end{array}$ & $\begin{array}{c}\text { Not aged } \\
\text { strength (MPa) } \\
\pm \text { Std dev. }\end{array}$ & $\begin{array}{c}\text { Aged without load } \\
\text { strength (MPa) } \\
\pm \text { Std dev. }\end{array}$ & $\begin{array}{c}\text { Aged with load } \\
\text { strength (MPa) } \\
\pm \text { Std dev. }\end{array}$ \\
\hline$[0]_{12}$ & 24 & $1940 \pm 276$ & $1865 \pm 44$ & $1848 \pm 49$ \\
{$[0]_{12}$} & -196 & $1287 \pm 207$ & $1568 \pm 59$ & $1536 \pm 126$ \\
{$[0]_{12}$} & -269 & $1495 \pm 326$ & $1451 \pm 243$ & $1771 \pm 186$ \\
{$[ \pm 25]_{3 \mathrm{~S}}$} & 24 & $1132 \pm 77$ & $1266 \pm 58$ & $955 \pm 84$ \\
{$[ \pm 25]_{3 \mathrm{~S}}$} & -196 & $912 \pm 49$ & $902 \pm 208$ & $1120 \pm 51$ \\
{$[ \pm 25]_{3 \mathrm{~S}}$} & -269 & $1131 \pm 15$ & 1114 & $1024 \pm 209$ \\
{$\left[45 / 90_{3} /-45 / \overline{0}_{3}\right]_{\mathrm{S}}$} & 24 & $711 \pm 14$ & $700 \pm 67$ & $843 \pm 38$ \\
{$\left[45 / 90_{3} /-45 / \overline{0}_{3}\right]_{\mathrm{S}}$} & -196 & $585 \pm 119$ & $748 \pm 57$ & $872 \pm 40$ \\
{$\left[45 / 900_{3} /-45 / \overline{0}_{3}\right]_{\mathrm{S}}$} & -269 & $656 \pm 48$ & $732 \pm 64$ & $806 \pm 2$ \\
{$[90]_{12}$} & 24 & $47 \pm 2$ & $47 \pm 3$ & NA \\
{$[90]_{12}$} & -196 & $21 \pm 4$ & $58 \pm 30$ & $63 \pm 5$ \\
{$[90]_{12}$} & -269 & $17 \pm 4$ & $11 \pm 5$ & NA \\
{$[ \pm 45]_{3 \mathrm{~S}}$} & 24 & $163 \pm 2$ & $165 \pm 0.5$ & $182 \pm 4$ \\
{$[ \pm 45]_{3 \mathrm{~S}}$} & -196 & $242 \pm 4$ & $249 \pm 3$ & $245 \pm 8$ \\
{$[ \pm 45]_{3 \mathrm{~S}}$} & -269 & $256 \pm 8$ & $257 \pm 12$ & $257 \pm 5$ \\
\hline \hline
\end{tabular}

(NA = not available) Note: Strength of $[ \pm 45]_{3 \mathrm{~S}}$ was defined as the initial point of deviation from the tangent of the nearly horizontal slope of the stress strain curve. 


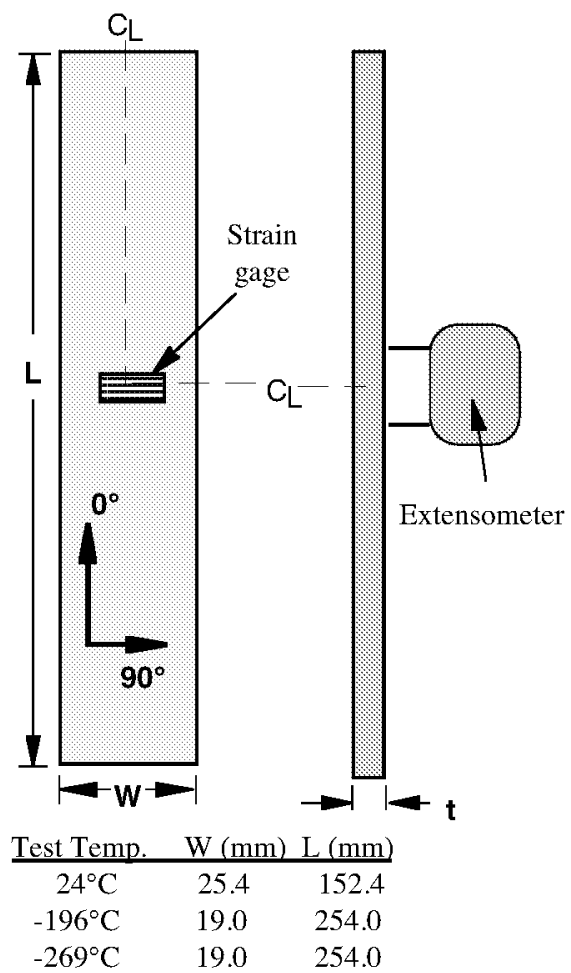

Figure 1. Schematic of test specimen

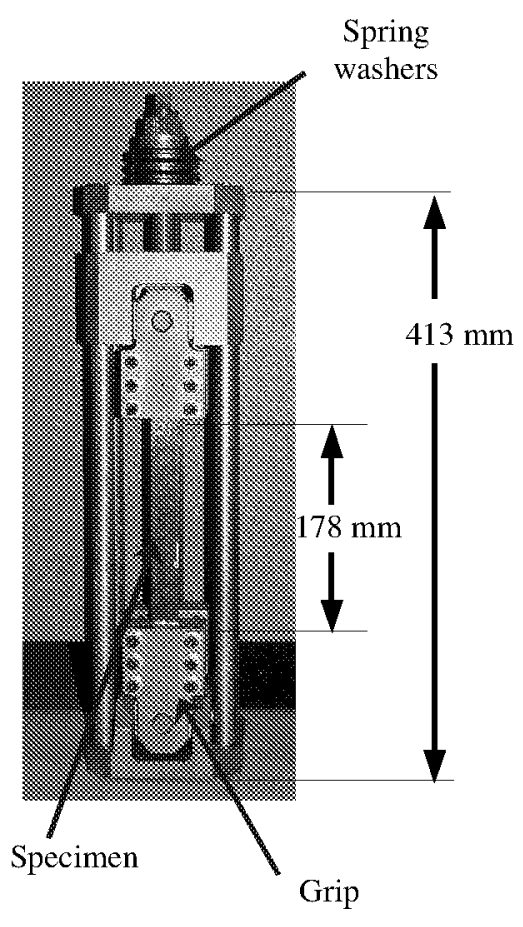

Figure 2. Constant strain aging fixture 
Not aged
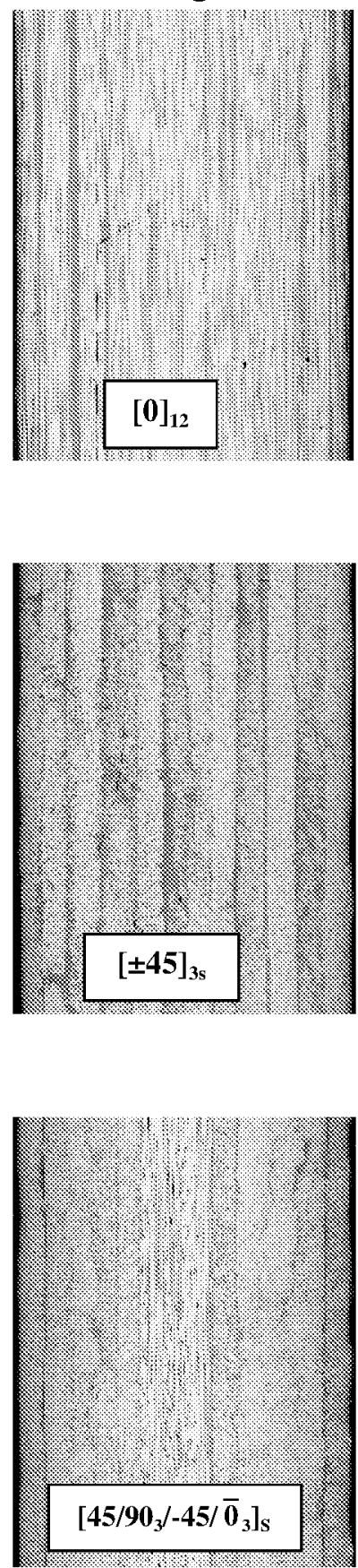

Aged without load

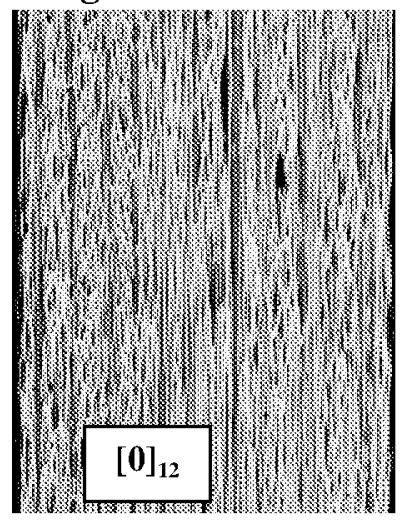

Aged with load

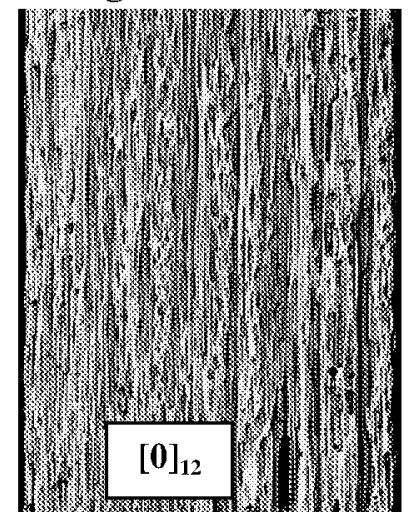

(a) Ply lay-up: $[0]_{12}$

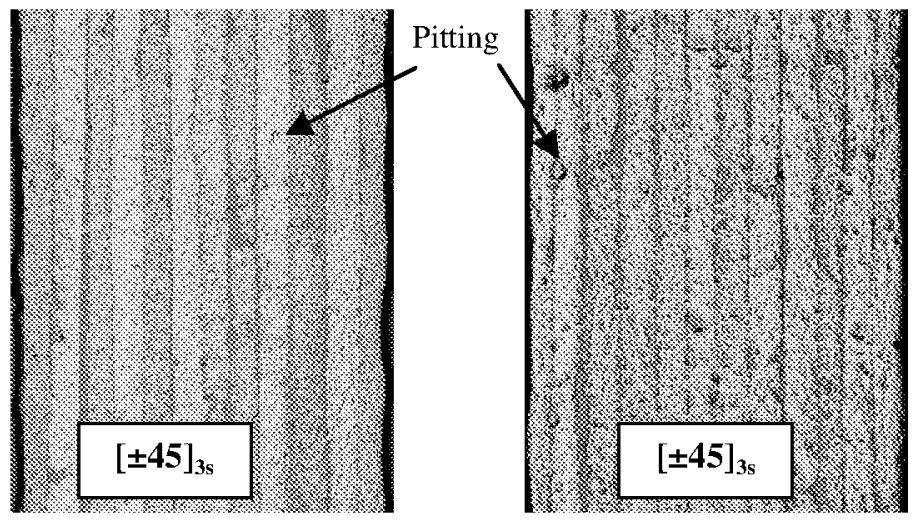

(b) Ply lay-up: $[+45]_{3 \mathrm{~s}}$
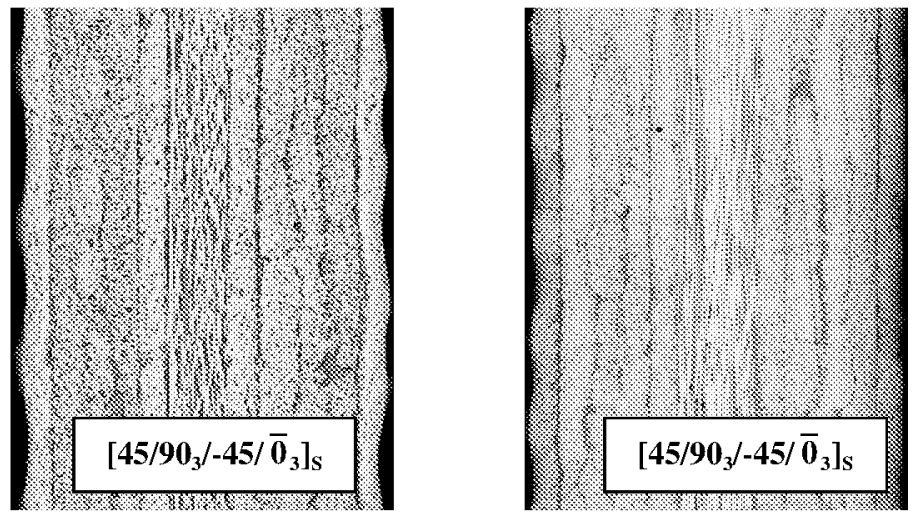

(c) Ply lay-up: $\left[45 / 90_{3} /-45 / \overline{0}_{3}\right]_{\mathrm{s}}$

Figure 3. Photomicrographs of specimen's edge prior to aging, after aging without load, and aging with load. 


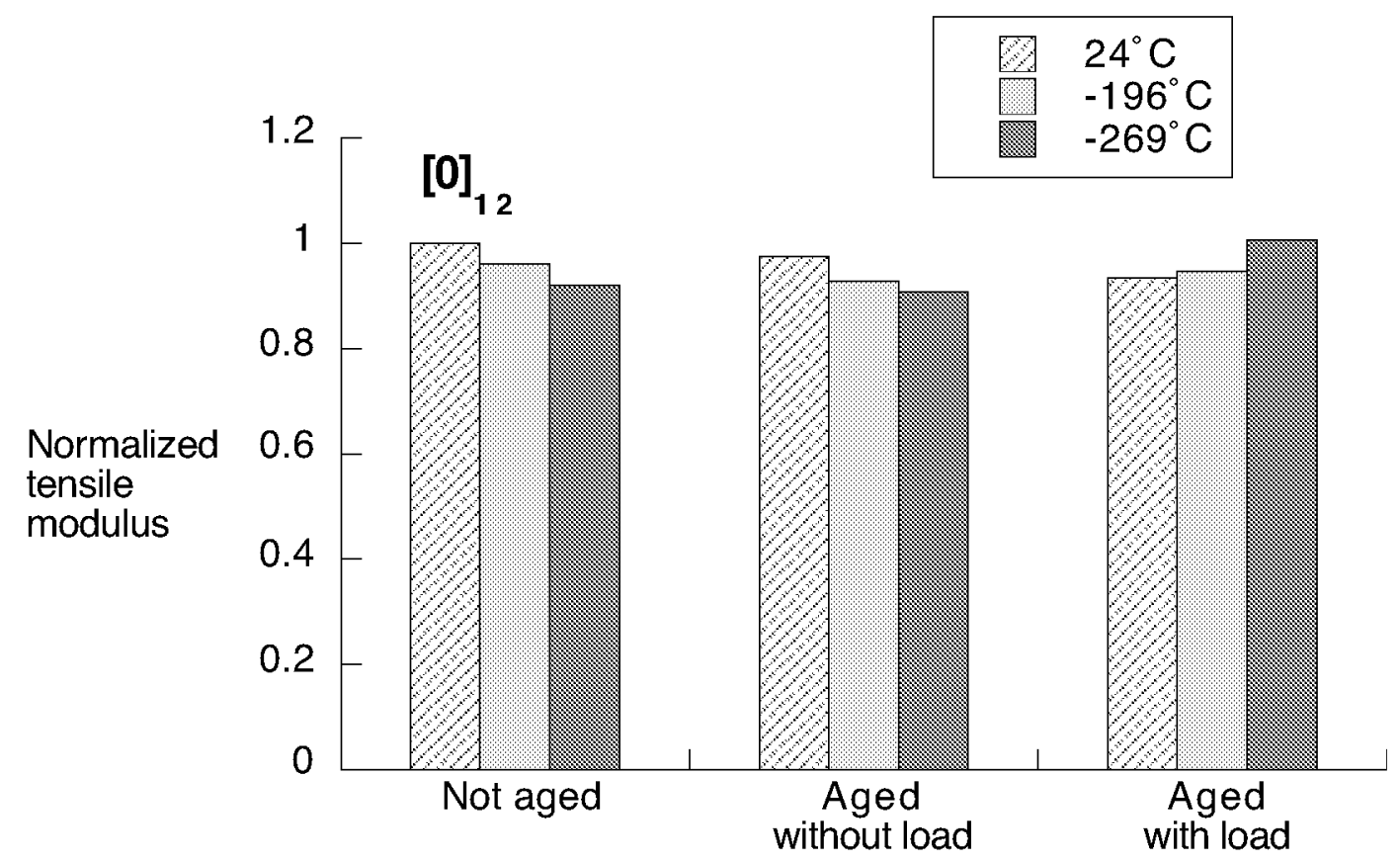

Figure 4. Modulus of specimens with $[0]_{12}$ ply lay-up normalized against the not aged condition tested at room temperature.

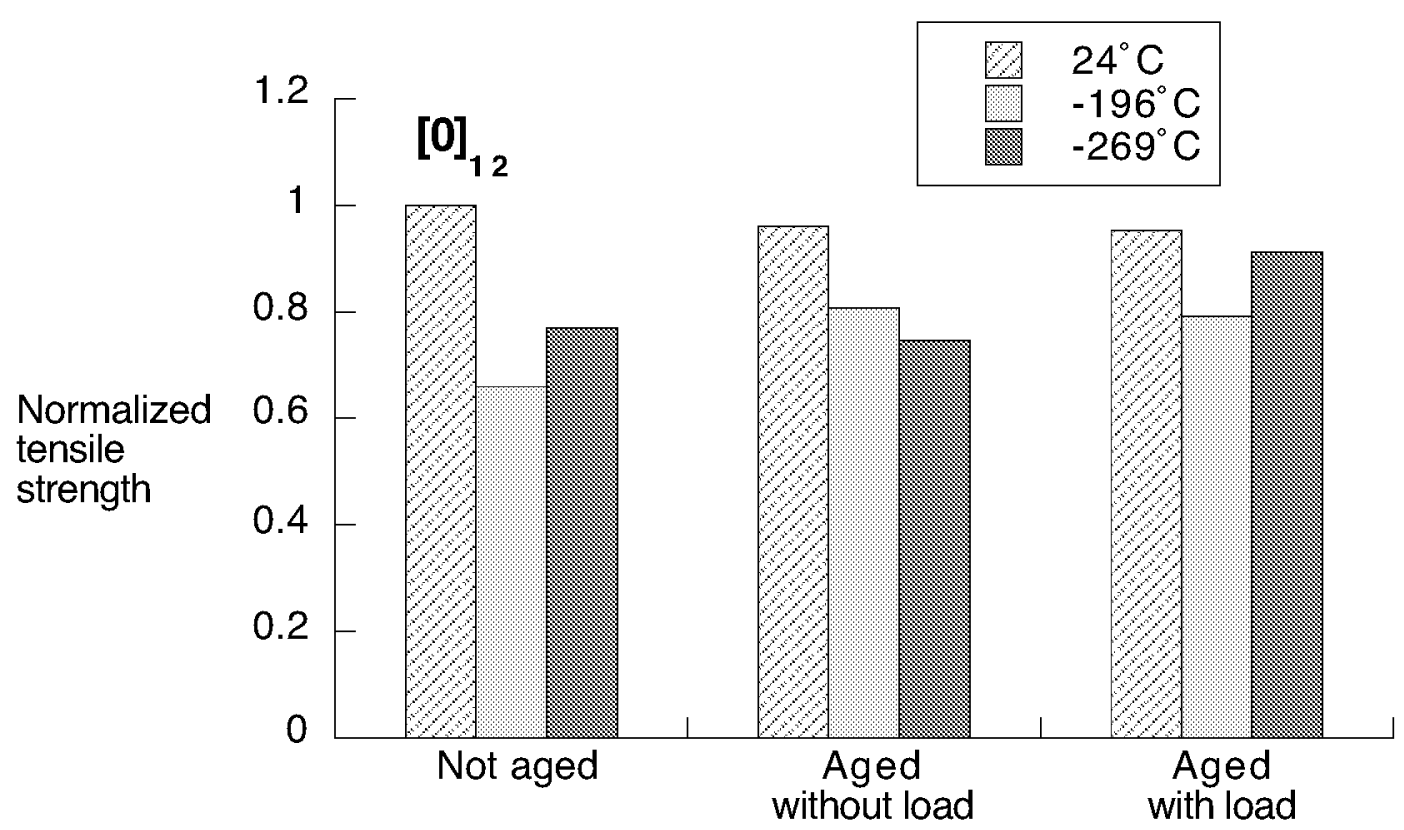

Figure 5. Strength of specimens with $[0]_{12}$ ply lay-up normalized against the not aged condition tested at room temperature. 


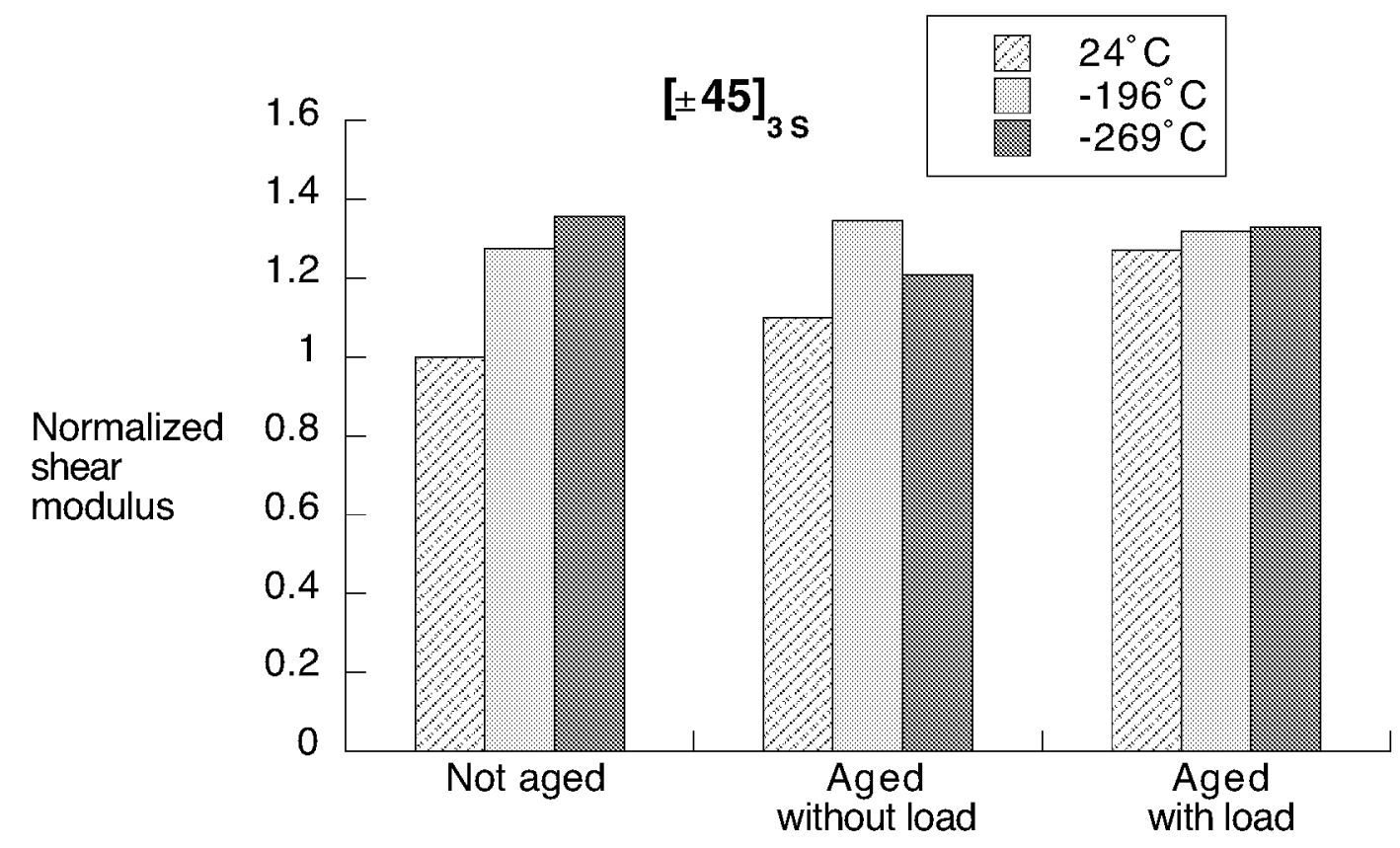

Figure 6. Shear modulus of specimens with $[ \pm 45]_{3 \text { s }}$ ply lay-up normalized against the not aged condition tested at room temperature.

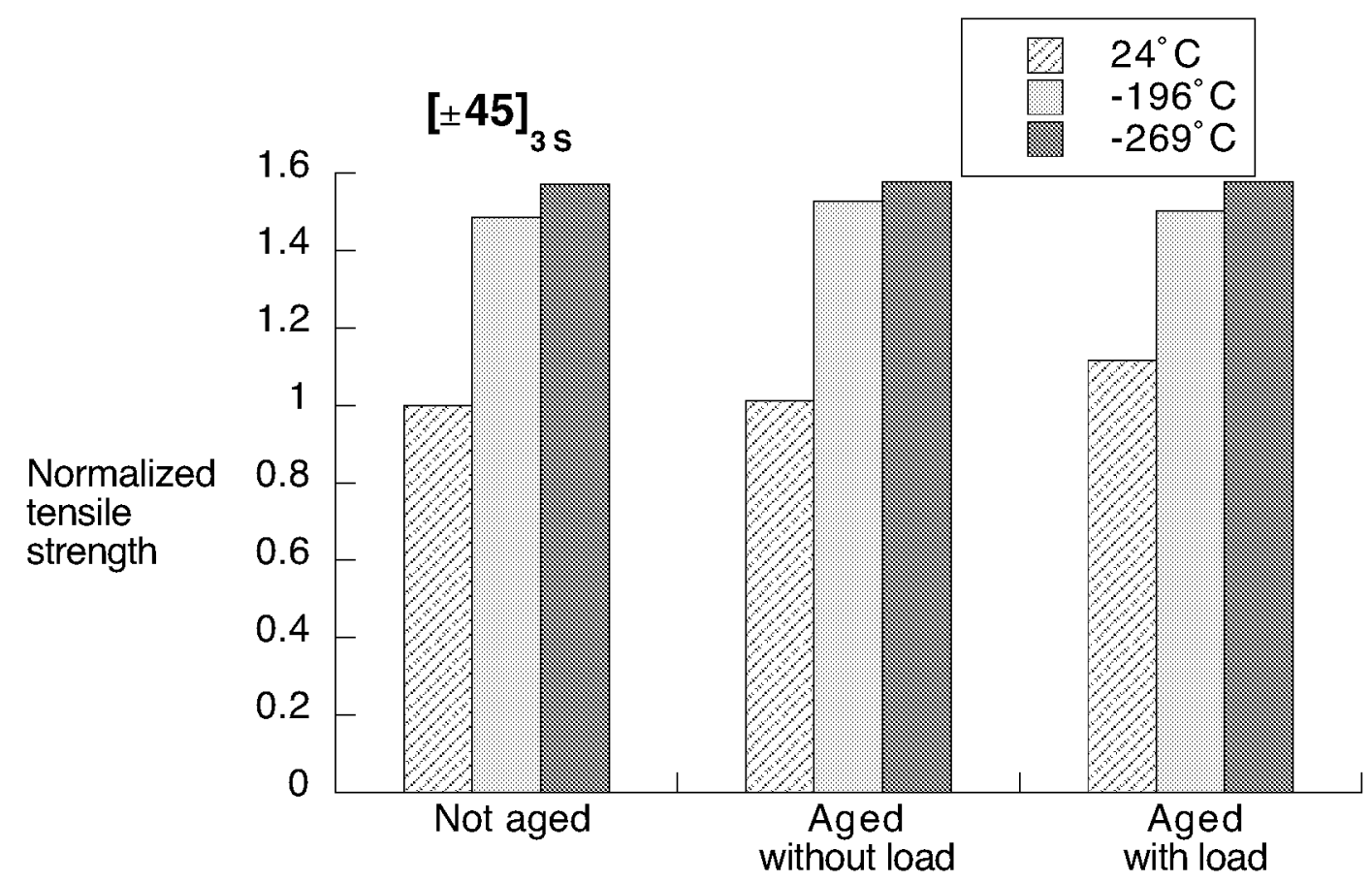

Figure 7 . Strength of specimens with $[+45]_{3 s}$ ply lay-up normalized against the not aged condition tested at room temperature. 


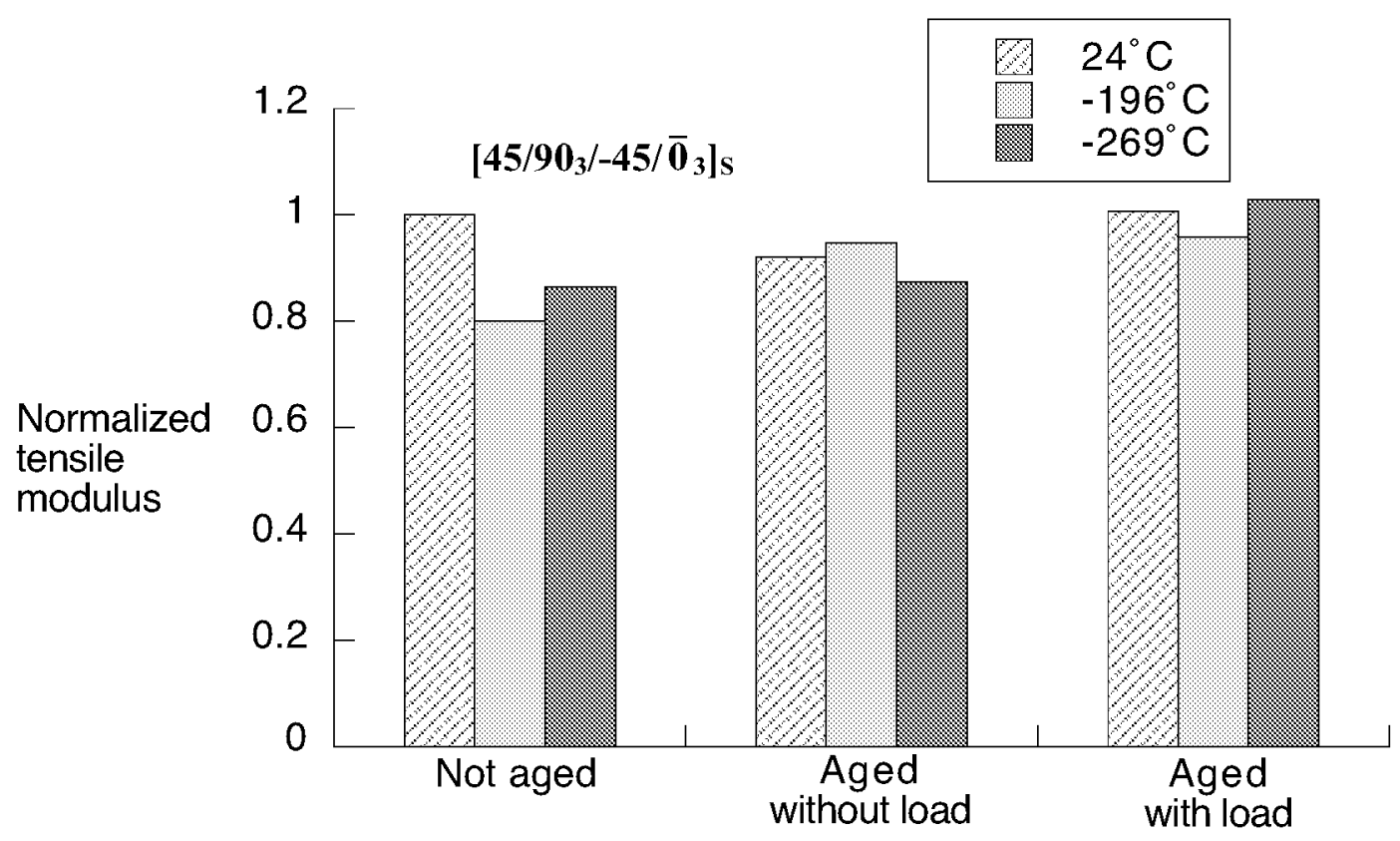

Figure 8 . Modulus of specimens with $\left[45 / 90_{3} /-45 / \overline{0}_{3}\right]_{\mathrm{s}}$ ply lay-up normalized against the not aged condition tested at room temperature.

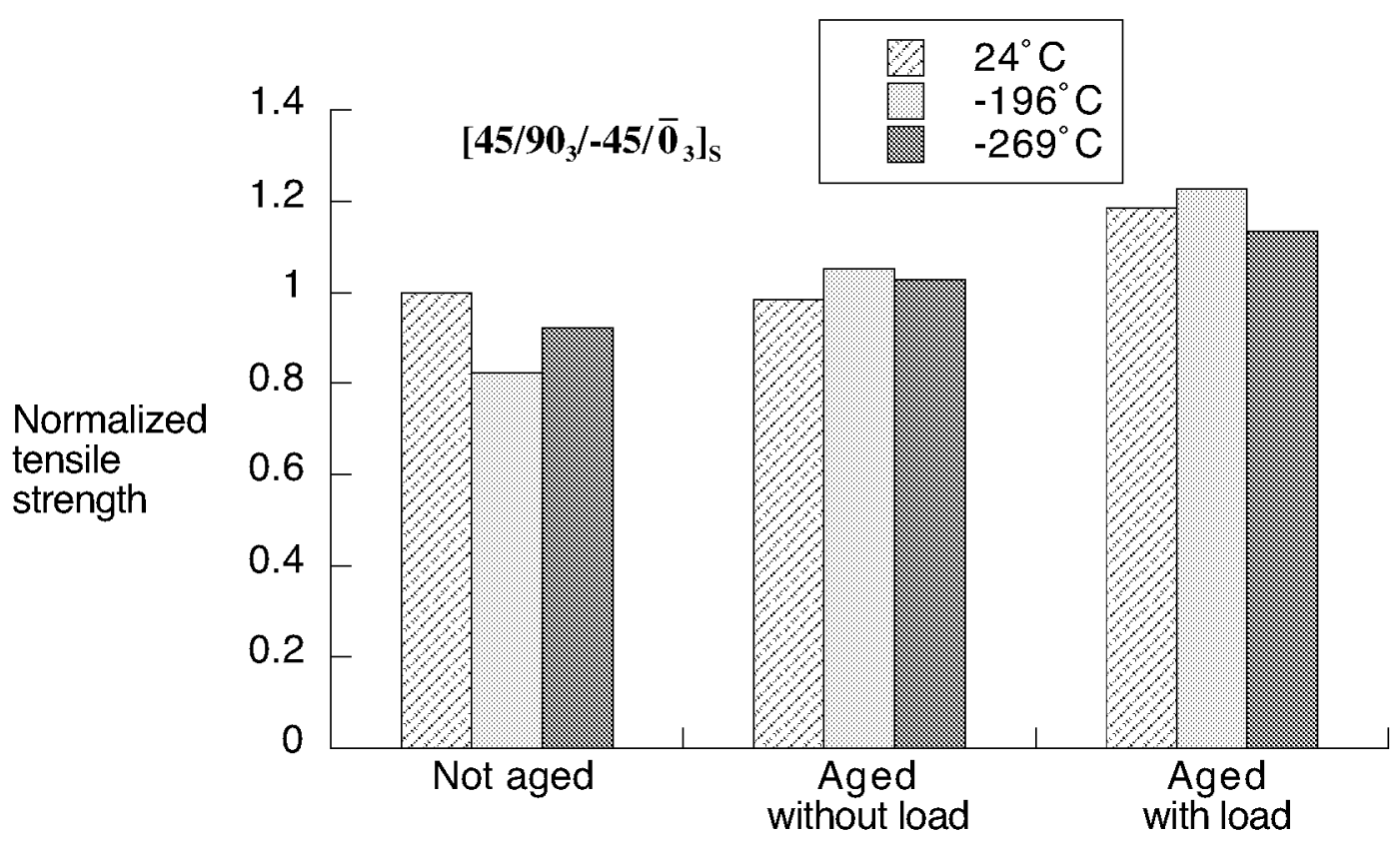

Figure 9 . Strength of specimens with $\left[45 / 90_{3} /-45 / \overline{0}_{3}\right]_{\mathrm{s}}$ ply lay-up normalized against the not aged condition tested at room temperature. 